\title{
Development of TPRT (Thermal Performance-Response Test) for Borehole Heat Exchanger Design
}

\section{Wonjun Choi}

Ryozo Ooka

\begin{abstract}
To obtain the effective thermal conductivity and borehole thermal resistance required to design borehole heat exchangers (BHEs), thermal response tests (TRTs) are usually conducted. Although many advanced TRT methods have been proposed, most TRTs cannot directly provide the actual thermal performance of an installed BHE. Because many uncertainties exist in constructing even conventional BHEs, examining the transient heat exchange rate allows inspection of the construction quality; the rate can also be used as a reference value for design. To determine the actual heat exchange rates of BHEs, it is necessary to conduct thermal performance tests (TPTs) under a constant inlet fluid temperature. However, TPT requires expensive equipment, including a water tank and a complex control system; thus, generally only TRT is conducted. To overcome the existing problems of TPT, in this study, we proposed a thermal performance-response test (TPRT) that combines TRT and TPT. This method involved the construction of a cost-effective TPRT apparatus by adding only a general PID controller and a solid-state relay to an existing TRT apparatus. Using the apparatus constructed by the proposed method, two TPRTs were conducted to confirm the performance of the apparatus and the validity of the TPRT method. Additionally, by defining the new parameter of the unit heat exchange rate, one potential simple and reliable design method for BHEs was explored.
\end{abstract}

\section{INTRODUCTION}

Thermal response tests (TRTs) are conducted to obtain the effective thermal conductivity of ground and the borehole thermal resistance, which are required to design borehole heat exchangers (BHEs). After Mogensen (Mogensen 1983) first proposed the idea of a TRT, many advanced TRT methods were developed (Acuña, et al. 2011; Fujii, et al. 2009; Raymond, et al. 2015). Although most TRTs can provide information regarding ground thermal properties, they cannot directly determine the actual thermal performance (i.e., the transient heat exchange rate) of constructed BHEs. After estimating the effective thermal conductivity of ground via TRT, the performance of a BHE can be estimated indirectly using numerical or analytical methods. However, this indirect estimation requires further data, such as the thermal properties of the backfill material and accurate geometric details of the BHE, which are not always available and can be difficult to obtain. If a ground-source heat pump (GSHP) is designed for intermittent operation, such unavailable information gains greater importance because it significantly affects the short-term performance and response of the BHE.

The temperature of the circulating fluid depends on the building load conditions and affects the heat exchange rate. Knowing the resulting heat exchange rate between the circulating fluid and ground is helpful for BHE design. For 
ground heat exchangers (GHEs) with complex geometries, such as energy piles with multiple U- or W-shaped pipes and helical-coil GHEs, the heat exchange rate is especially helpful because the performance of such complex-geometry GHEs differs from that of conventional BHEs and the design method is not well established. To obtain the actual thermal performance of a complex-geometry GHE, a thermal performance test (TPT), which maintains a constant inlet fluid temperature, is usually conducted. To investigate the thermal performance of various types of GHEs, several TPTs have been reported (Gao, et al. 2008a, 2008b; Li, et al. 2006; Wang, et al. 2009). In addition to examining the performance of complex shape GHEs, TPTs can also be used to examine the actual performance of an installed conventional BHE. Obtaining the heat exchange rate is important because many uncertainties affect the construction and design of BHEs, such as the geometry of the U-tubes (torsion and bending of pipe legs), uneven packing of the grouting or backfill, unverified subsurface heat-transfer phenomena, and uncertain ground properties, as noted in Bernier (2002); Raymond, et al. (2011); Spitler and Gehlin (2015); Witte (2013).

As described above, although the information from TPT is as important as that from TRT, conducting both TRT and TPT is atypical because they require different apparatus. Typically, only TRTs are conducted. To overcome this situation, we propose a method that combines the TRT and TPT, termed the thermal performance-response test (TPRT). The proposed method is accompanied by a new apparatus and estimation method. Compared to the total cost of constructing conventional TRT apparatus, which generate constant heat rates from heaters, the proposed apparatus can be constructed with an additional cost of only $\$ 300-400$, and the estimation can be conducted using the well-known infinite line source (ILS) model (Carslaw and Jaeger 1959; Ingersoll, et al. 1954) and a numerical optimization method. Therefore, the proposed apparatus and estimation method are practically appealing.

In this work, we constructed a TPRT apparatus using an existing conventional TRT apparatus. Two TPRTs with different inlet temperatures $\left(25^{\circ} \mathrm{C}\right.$ and $\left.30^{\circ} \mathrm{C}\right)$ were conducted, and the estimation results were validated using previous TRT results. Additionally, a new parameter, termed the unit heat exchange rate $Q_{u}$, was proposed to predict GHE performance under certain operation conditions.

\section{EXPERIMENTAL SETUP AND TPRT APPARATUS}

TPRTs were applied to a BHE installed at the Chiba Experimental Station at the University of Tokyo (Inage Ward, Chiba, Japan). The site was stratigraphically divided into a top layer of loam and clay up to a depth of $8 \mathrm{~m}$, followed by fine sand, silt, and fine sand again between the depths of 8-25 m, 25-31 m, and 31-60 m, respectively. The depth-averaged undisturbed ground temperature varied seasonally at around $17^{\circ} \mathrm{C}$. The BHE had an effective depth of $50 \mathrm{~m}$, and the borehole had a diameter of $165 \mathrm{~mm}$. A single high-density polyethylene U-tube with outer and inner diameters of 34 and $27 \mathrm{~mm}$, respectively, was inserted into the borehole. The thermal conductivity of the U-tube was $0.38 \mathrm{~W} /(\mathrm{m} \cdot \mathrm{K})$. To maintain a shank spacing of $50 \mathrm{~mm}$, spacers were attached between the U-tube legs at $10 \mathrm{~m}$ intervals. The borehole was grouted with Portland cement mixed with 20\% silica sand. Water was used as the heat carrier fluid. More details can be found in (Choi and Ooka 2016a, 2015).

Reported TPT apparatus use water tanks as thermal buffers; researchers note that complex control systems are required, and the resulting high cost makes TPT apparatus impractical (Gao, et al. 2008a; Li, et al. 2006; Wang, et al. 2010). The apparatus proposed in this study does not require a water tank; only a solid-state relay (SSR) and a general proportional-integral-derivative (PID) controller are required to control the inlet fluid temperature. A schematic of the proposed system is shown in Figure 1. The process variable of this system is the inlet fluid temperature (outlet temperature of the TPRT apparatus), which is measured by a PT-100 sensor. Depending on the fluid temperature passing through the heaters, the PID controller calculates the desired power output and then sends signals to the SSR to regulate the power output of the heaters. Because the proposed method does not use a chiller, the apparatus cannot be used for heat extraction tests. However, compared to a conventional TRT apparatus, the additional cost is only approximately $\$ 300-400$. Moreover, the proposed control system can be easily applied to any existing TRT apparatus.

In this study, to obtain good controllability, three coefficients-P, I, and D-were selected based on trial and error. The P, I, and D coefficients were set to 6,64 , and 15 , respectively. The heaters installed in the existing TRT 
apparatus had power outputs of 1,2 , and $4 \mathrm{~kW}$. The total output was $7 \mathrm{~kW}$.

When the set point temperature is $25^{\circ} \mathrm{C}$ and the initial ground temperature is $17.7^{\circ} \mathrm{C}$, the rise time required to reach the set point temperature from the beginning of the test is approximately $6 \mathrm{~min}$, and the amount of overshoot is only $0.45^{\circ} \mathrm{C}$ (Figure 2). For higher-power heaters, a faster rise time can be expected. After an elapsed test time of 15 min, the temperature difference between the set point and inlet temperature is less than $0.2^{\circ} \mathrm{C}$. After an elapsed test time of $1 \mathrm{~h}$, the temperature difference is less than $0.1^{\circ} \mathrm{C}$; this error can be regarded as a steady-state error of the control system. The developed TPRT apparatus shows that sufficiently fast, accurate, and robust control can be achieved without a water tank and complex control logic.

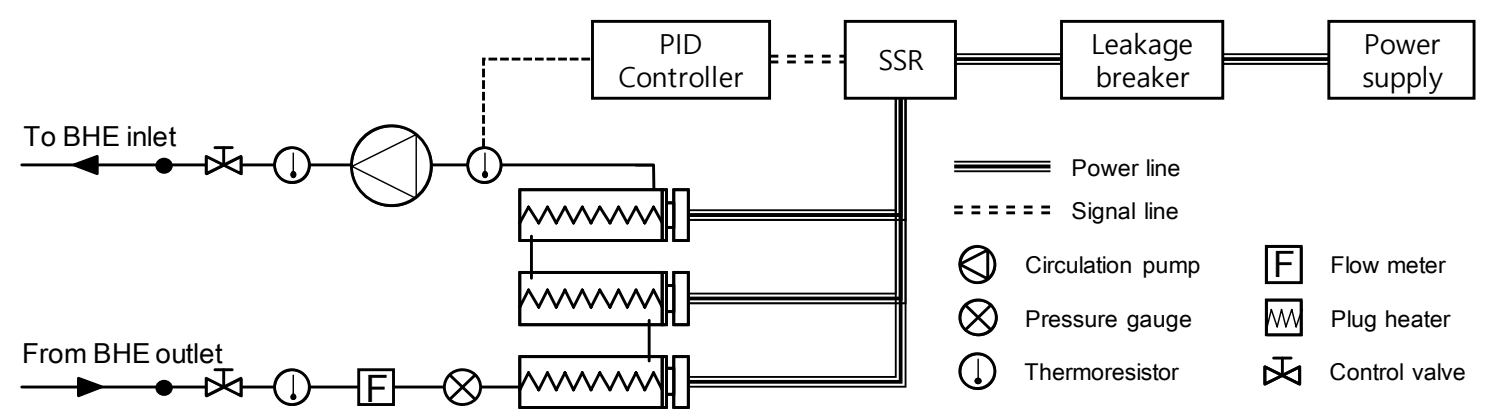

Figure 1 Schematic of TPRT system.

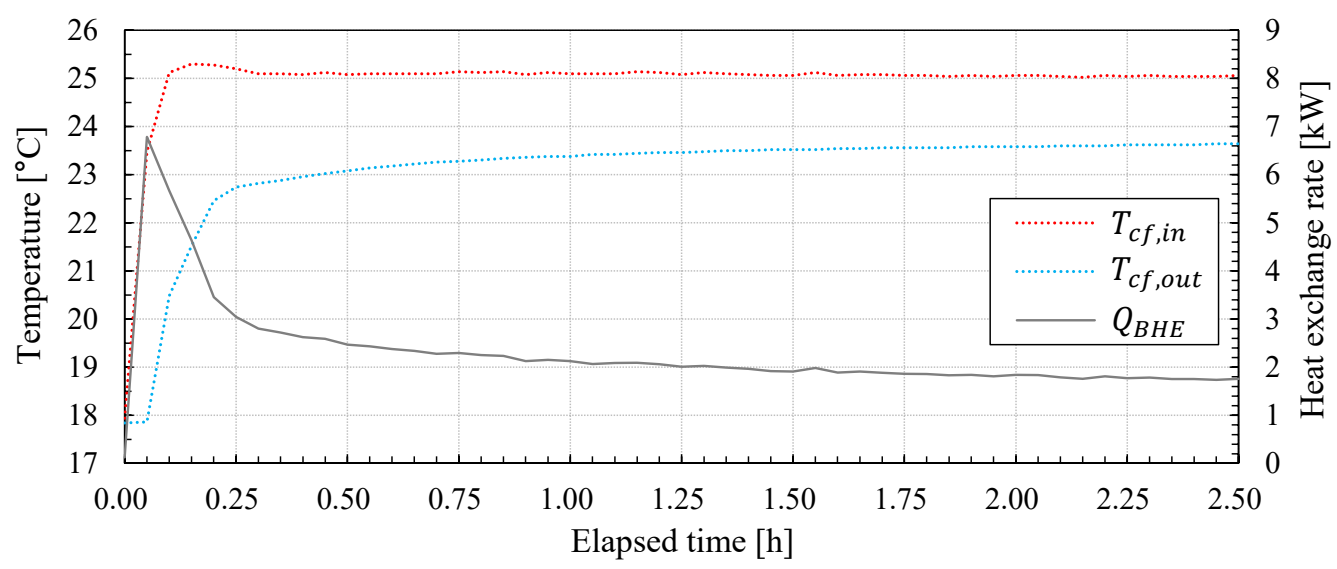

Figure 2 Early time temperature response and heat exchange rate (set point temperature is $25^{\circ} \mathrm{C}$ ).

\section{PARAMETER ESTIMATION METHOD}

The parameter estimation method in this study used the infinite line source (ILS) model (Carslaw and Jaeger 1959; Ingersoll, et al. 1954) as a physical model that reproduced the thermal response of the BHE and the quasi-Newton method as a numerical optimization algorithm. To consider the continuously varying heat exchange rate of TPRT, a temporal superposition of heat pulses was applied to the ILS model. The temporal superposition-applied ILS model with respect to the average fluid temperature $\bar{T}_{c f, c a l}$ can be expressed as follows: 


$$
\bar{T}_{c f, c a l}(t)=\sum_{n=1}^{N} \frac{q_{n}-q_{n-1}}{4 \pi \lambda_{e f f}} \operatorname{Ei}\left(\frac{C_{s} r_{b}^{2}}{4 \lambda_{e f f}\left(t_{N}-t_{n-1}\right)}\right)+R_{b} \cdot q_{N}+T_{0}
$$

where $q_{0}=0 \mathrm{~W} / \mathrm{m}$ and $t_{0}=0$.

The volumetric heat capacity of soil $C_{S}$ was assumed to be $2.8 \mathrm{MJ} / \mathrm{m}^{3} \mathrm{~K}$. The depth-averaged undisturbed ground temperature $T_{0}$ was measured by circulating water in the $\mathrm{BHE}$ without heat generation. It varied according to the outdoor environment in the range of $16.5-17.0^{\circ} \mathrm{C}$. However, because the water in the aboveground hydraulic circuit is affected by the outdoor environment, the measured $T_{0}$ is higher than $17.0^{\circ} \mathrm{C}$ and lower than $16.5^{\circ} \mathrm{C}$ in summer and winter seasons, respectively. The transient heat exchange rate per unit length of the BHE $q$ can be obtained from the flow rate $\dot{V}_{c f}$, inlet temperature $T_{c f, \text { in }}$, and outlet temperature $T_{c f, \text { out }}$.

$$
q=Q_{B H E} / H=\rho_{c f} c_{c f} \dot{V}_{c f}\left(T_{c f, \text { in }}-T_{c f, o u t}\right) / H
$$

The heat exchange rate per unit length of BHE at a certain time step, $q_{n}$, is a time-varying value. The heat rate $q$ is regarded as squared pulses obtained by averaging the $q$ values measured at 5-s intervals over a 2 -h period.

The calculated average fluid temperature $\bar{T}_{c f, c a l}$ is a function of two unknown variables: the effective thermal conductivity $\lambda_{\text {eff }}$ and the borehole thermal resistance $R_{b}$. By minimizing the difference between the calculated fluid temperature $\bar{T}_{c f, c a l}$ and measured fluid temperature $\bar{T}_{c f, \exp }$ to less than $10^{-5}$ for every 2 -h interval of time step, both $\lambda_{e f f}$ and $R_{b}$ can be estimated. The objective function and stopping criterion are described in Eq. (3).

$$
\begin{aligned}
& f_{o b j}\left(\lambda_{e f f}, R_{b}\right)=\left(\bar{T}_{c f, e x p}-\bar{T}_{c f, c a l}\left(\lambda_{e f f}, R_{b}\right)\right)^{2} \\
& f_{o b j}\left(\lambda_{e f f}, R_{b}\right) \leq 10^{-5}
\end{aligned}
$$

This objective function was minimized using the quasi-Newton method, and the Broyden-Fletcher-GoldfarbShanno (BFGS) method was used to approximate the Hessian. To enhance the speed of the estimation and alleviate the ill-posed nature of the parameter estimation, the search range was restricted based on the initial guess values of each time step, $\lambda_{\text {eff,ini }} \pm 0.5 \mathrm{~W} /(\mathrm{m} \cdot \mathrm{K})$ and $R_{b, i n i} \pm 0.05 \mathrm{~m} \cdot \mathrm{K} / \mathrm{W}$. From the second time step onward, the estimated values of the previous time step were used as the initial guess values for the current time step. The details and advantages of the method can be found in Choi and Ooka (2015).

\section{APPLICATION OF IN SITU TPRT}

Two TPRTs were conducted for $96 \mathrm{~h}$. The experimental conditions, average flow rate, and average heat exchange rate are summarized in Table 1. The set point inlet temperatures were $25{ }^{\circ} \mathrm{C}$ (TPRT_25) and $30{ }^{\circ} \mathrm{C}$ (TPRT_30), respectively. The temperature response and heat exchange rate are shown in Figure 3 . The inlet temperatures of both TPRT_25 and TPRT_30 are very stable. Unlike in TRT, the diurnal disturbance of the outdoor environment, which affects the temperature response, was well controlled. Immediately after noon, when the disturbed heat flux was the highest because of solar irradiation (Choi and Ooka 2016b, 2016c), the inlet temperature was slightly perturbed. However, the largest error of the inlet temperature was less than $0.18^{\circ} \mathrm{C}$ from $3 \mathrm{~h}$ to the end of test time, which can be considered steady-state control. Considering that logging was conducted at 5-s intervals, the results imply very good controllability of the developed apparatus, and thus, the TPRT can be conducted without a water tank or complex control system. 
Table 1. Experimental Conditions of TPRT

\begin{tabular}{ccccc}
\hline Test name & Set point temperature $\left[{ }^{\circ} \mathbf{C}\right]$ & Duration $[\mathbf{h}]$ & Flow rate [L/min] & Average heat rejection rate [W] \\
\hline \hline TPRT_25 & 25 & 96 & 17.77 & 1193 \\
TPRT_30 & 30 & 96 & 18.07 & 1965 \\
\hline
\end{tabular}

Both tests show approximately $7 \mathrm{~kW}$ for the heat exchange rate immediately after the experiments begin, but this rate decreases rapidly. At the final elapsed time of $96 \mathrm{~h}$, the heat exchange rates of TPRT_25 and TPRT_30 are 1.03 $\mathrm{kW}$ and $1.69 \mathrm{~kW}$, respectively. After about $12 \mathrm{~h}$, the heat rate decreases linearly with the logarithm of time.

Estimations were conducted using the average fluid temperature (Figure 3) and Eq. (1)-(3). Because the earlytime response dominated by the BHE itself cannot be accurately reproduced by the ILS model, which is derived based on the assumption of a homogeneous medium, estimations were conducted from $12 \mathrm{~h}$ onward. The estimation results are shown in Figure 4, and the final estimated values are listed in Table 2. The estimation behavior is stable, and the estimated values are very close to the values obtained from TRTs conducted in 2015 at the same site (Choi and Ooka 2016a, 2016c) as listed in Table 2.

Although the estimations in this study were successful, for TPRT on other GHEs, parameters should be estimated carefully. Parameter estimation requires a physical model that can appropriately reproduce the temperature response of the GHE. Using an inadequate model would produce unreliable estimated values.
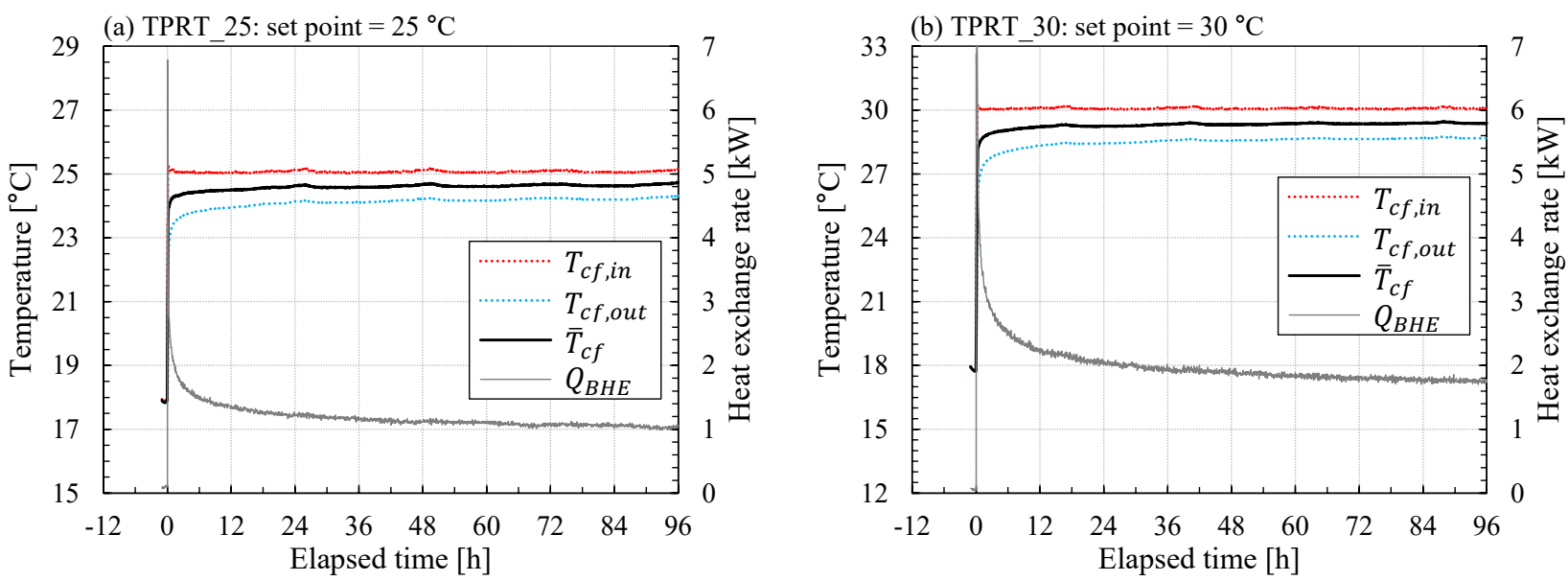

Figure 3 Temperature responses and heat exchange rates of two TPRTs ((a) TPRT_25 and (b) TPRT_30).

Table 2. Estimated Thermal Conductivity and Borehole Thermal Resistance

\begin{tabular}{|c|c|c|c|c|c|}
\hline Test name & $\begin{array}{c}\text { Initial guess } \lambda_{\text {eff }} \text { and } R_{b} \\
\text { for estimation } \\
{[\mathrm{W} /(\mathrm{m} \cdot \mathrm{K})],[\mathrm{m} \cdot \mathrm{K} / \mathrm{W}]}\end{array}$ & $\begin{array}{l}\text { Final } \lambda_{e f f} \\
{[\mathrm{~W} /(\mathrm{m} \cdot \mathrm{K})]}\end{array}$ & $\begin{array}{l}\text { Final } R_{b} \\
{[\mathrm{~m} \cdot \mathrm{K} / \mathrm{W}]}\end{array}$ & $\begin{array}{c}\lambda_{e f f} \text { of } \\
\text { past TRTs } \\
{[\mathrm{W} /(\mathrm{m} \cdot \mathrm{K})]} \\
\end{array}$ & $\begin{array}{c}R_{b} \text { of } \\
\text { past TRTs } \\
{[\mathrm{m} \cdot \mathrm{K} / \mathrm{W}]} \\
\end{array}$ \\
\hline TPRT_25 & $1.9,0.15$ & 1.91 & 0.150 & \multirow{2}{*}{$1.86-1.98$} & \multirow{2}{*}{$0.146-0.159$} \\
\hline TPRT_30 & $1.9,0.15$ & 1.95 & 0.149 & & \\
\hline
\end{tabular}



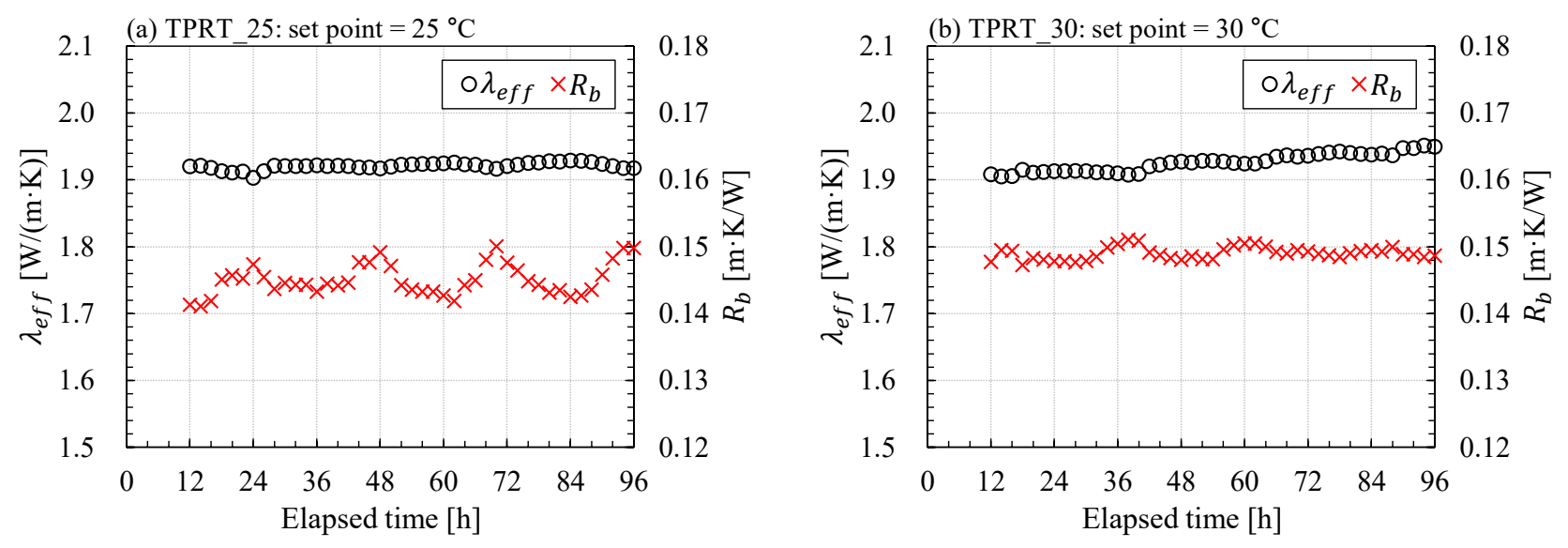

Figure 4 Estimation results of the two TPRTs ((a) TPRT_25, and (b) TPRT_30).
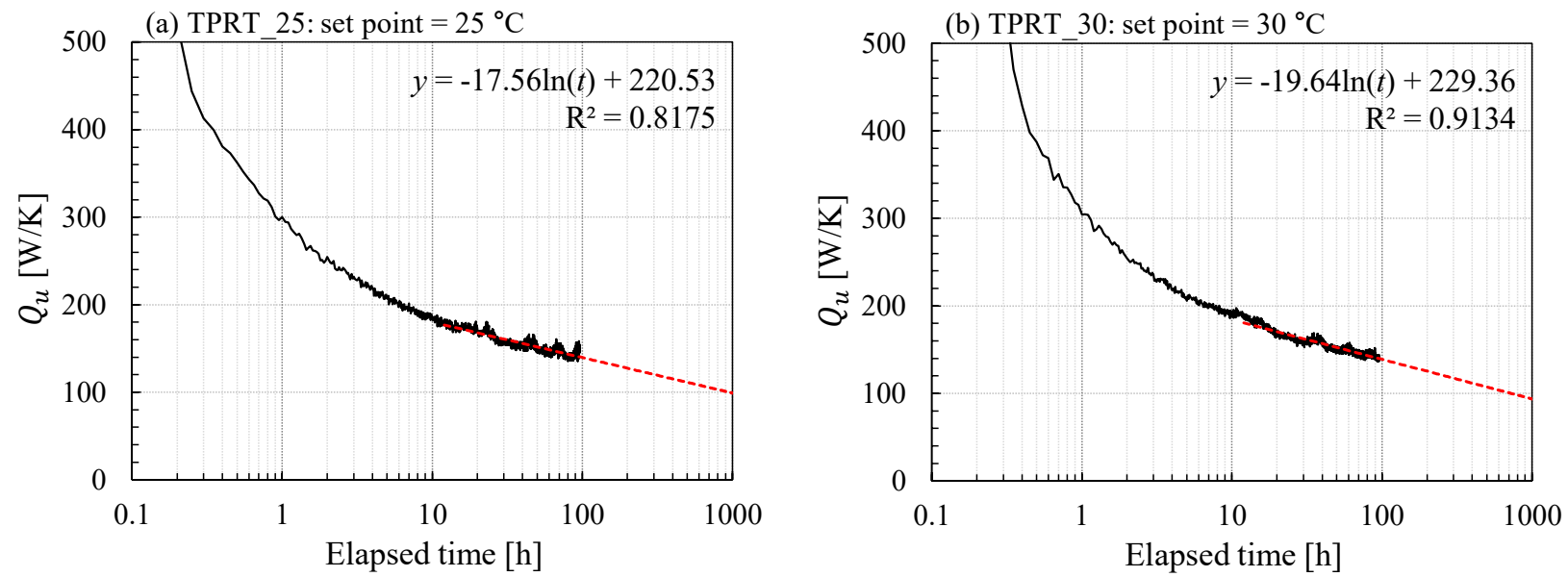

Figure 5 Semi-log plot of unit heat exchange rate and linear regression using data from 12-96 h ((a) TPRT_25, and (b) TPRT_30).

Because the heat exchange rate obtained from TPRT reflects all uncertain and unknown factors, such as the Utube position, construction quality, and other unknown and neglected physical phenomena (e.g., natural convection and advection), it is valuable and reliable in indicating the performance of the installed GHE. Additionally, this value can be used for the simple and reliable prediction of GHE performance under certain operation conditions. To utilize the obtained heat exchange rate from TPRT, we define a new parameter that describes the heat exchange rate of GHE per unit temperature difference. We divide the heat exchange rate $Q_{G H E}$ obtained from TPRT by the absolute temperature difference between the average fluid temperature $\bar{T}_{c f}$ and the undisturbed ground temperature $T_{0}$. We name this value the unit heat exchange rate $Q_{u}[\mathrm{~W} / \mathrm{K}]$, which is expressed as follows: 


$$
Q_{u}(t)=q_{u}(t) \cdot H=\frac{Q_{G H E}(t)}{\left|\bar{T}_{c f}(t)-T_{0}\right|}
$$

Assuming that the undisturbed ground temperature is $17^{\circ} \mathrm{C}$, we calculated $Q_{u}$ for two TPRTs using Eq. (4); the semi-logarithmic plots of $Q_{u}$ are shown in Figure 5. Regardless of the inlet set temperatures, the two graphs show very similar behaviors. This means that the obtained $Q_{u}$ can be extended to predict other operating conditions with different fluid temperatures. However, this extension may not hold if there is strong subsurface advection by groundwater flow.

The red dashed line in Figure 5 represents the linear regression of $Q_{u}$ using the data collected from 12-96 h. From the regression line, we find that $Q_{u}$ decreases linearly and it can be extended for a longer operation. Based on the findings of $Q_{u}$, we can use the TPRT for a simple performance prediction of the GHE under a certain operating condition. For example, if we know the length and magnitude of heat load $t_{l}$ and $Q_{l}$, respectively, then we can calculate the fluid temperature using an analytical or numerical response model with known thermal properties estimated from TPRT. By calculating $Q_{u}\left(t_{l}\right) \cdot\left|\bar{T}_{c f}\left(t_{l}\right)-T_{0}\right|$, the performance of the GHE under specific operating conditions can be easily predicted.

To extend this performance prediction method to the design of GHEs, further studies should be conducted. In the ASHRAE design method (ASHRAE 2007; Philippe, et al. 2010) for BHEs, three different heat pulses for yearly, monthly, and hourly time scales are required. If the yearly and monthly average heat pulses can be appropriately converted to the hourly pulse and, correspondingly, the length of the hourly pulse is modified, a new and simple design becomes possible.

\section{CONCLUSION}

In this study, using a general PID controller and an SSR, a cost-competitive TPRT apparatus was developed. The developed apparatus showed excellent controllability. Using the developed apparatus, two TPRTs were conducted on a $\mathrm{BHE}$ to obtain the transient heat exchange rates and estimate the effective thermal conductivity and borehole thermal resistance. The estimation results were very close to the estimated values from past TRTs at the same site.

Additionally, by defining the unit heat exchange rate $Q_{u}$, the possibility of a simple and reliable design method for GHEs was identified, and a draft of this new method was proposed. Some issues pertaining to the unit heat exchange rate were outlined, which require further examination and discussion.

\section{ACKNOWLEDGMENTS}

We wish to acknowledge the financial support from the New Energy and Industrial Technology Development Organization and the Research Fellowship program for Overseas Researchers from the Japan Society for the Promotion of Science for Young Scientists (Grant Number P16074)

\section{NOMENCLATURE}

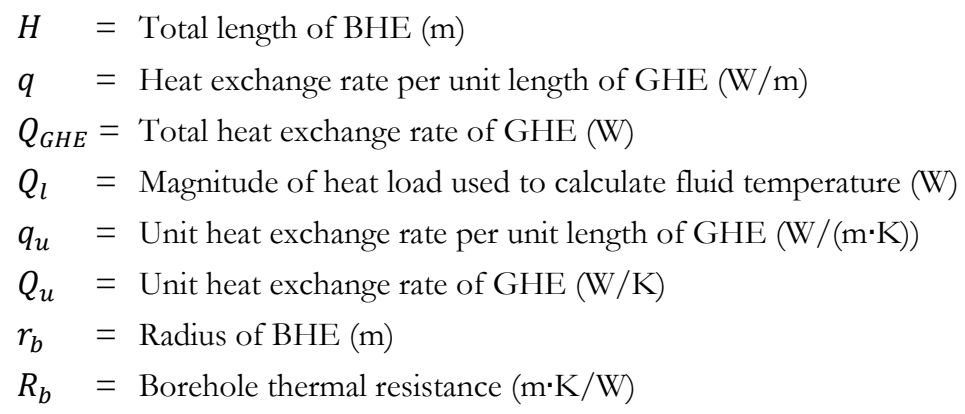


$t_{l}=$ Length of heat load used to calculate fluid temperature and unit heat exchange rate $(\mathrm{h})$

$\bar{T}_{c f}=$ Average temperature of circulating fluid $\left({ }^{\circ} \mathrm{C}\right)$

$\dot{V}_{c f}=$ Volumetric flow rate of circulating fluid $\left(\mathrm{m}^{3} / \mathrm{s}\right)$

$\lambda_{\text {eff }}=$ Effective thermal conductivity of ground $(\mathrm{W} /(\mathrm{m} \cdot \mathrm{K}))$

\section{Subscripts}

$$
\begin{array}{ll}
c f & =\text { circulating fluid } \\
n & =\text { n-th time step }
\end{array}
$$

\section{REFERENCES}

Acuña, J., Mogensen, P., and Palm, B. 2011. Distributed thermal response tests on a multi-pipe coaxial borehole heat exchanger. HVAC\&R Research, 17(6):1012-1029.

Bernier, M. 2002. Uncertainty in the design length calculation for vertical ground heat exchangers. ASHRAE Transactions, 108:939-944.

Carslaw, H. S., and Jaeger, J. C. 1959. Conduction of Heat in Solids. Oxford University Press (2nd ed.). UK: Oxford University Press.

Choi, W., and Ooka, R. 2015. Interpretation of disturbed data in thermal response tests using the infinite line source model and numerical parameter estimation method. Applied Energy, 148:476-488.

Choi, W., and Ooka, R. 2016a. Effect of disturbance on thermal response test, part 1: Development of disturbance analytical model, parametric study, and sensitivity analysis. Renewable Energy, 85:306-318.

Choi, W., and Ooka, R. 2016b. Effect of disturbance on thermal response test, part 2: Numerical study of applicability and limitation of infinite line source model for interpretation under disturbance from outdoor environment. Renewable Energy, 85:1090-1105.

Choi, W., and Ooka, R. 2016c. Effect of natural convection on thermal response test conducted in saturated porous formation: Comparison of gravel-backfilled and cement-grouted borehole heat exchangers. Renewable Energy, 96:891-903.

Fujii, H., Okubo, H., Nishi, K., Itoi, R., Ohyama, K., and Shibata, K. 2009. An improved thermal response test for U-tube ground heat exchanger based on optical fiber thermometers. Geothermics, 38(4):399-406.

Gao, J., Zhang, X., Liu, J., Li, K. S., and Yang, J. 2008a. Thermal performance and ground temperature of vertical pile-foundation heat exchangers: A case study. Applied Thermal Engineering, 28(17-18):2295-2304.

Gao, J., Zhang, X., Liu, J., Li, K., and Yang, J. 2008b. Numerical and experimental assessment of thermal performance of vertical energy piles: An application. Applied Energy, 85(10):901-910.

Ingersoll, L. R., Zobel, O. J., and Ingersoll, A. C. 1954. Heat conduction with engineering, geological, and other applications. University of Wisconsin Press. Madison: University of Wisconsin Press.

Li, X., Chen, Y., Chen, Z., and Zhao, J. 2006. Thermal performances of different types of underground heat exchangers. Energy and Buildings, 38(5):543-547.

Mogensen, P. 1983. Fluid to duct wall heat transfer in duct system heat storages. In Proceedings of International Conference on Subsurface Heat Storage in Theory and Practice (pp. 652-657). Stockholm, Sweden: Swedish Council for Building Research.

Raymond, J., Lamarche, L., and Malo, M. 2015. Field demonstration of a first thermal response test with a low power source. Applied Energy, 147:30-39.

Raymond, J., Therrien, R., Gosselin, L., and Lefebvre, R. 2011. A Review of Thermal Response Test Analysis Using Pumping Test Concepts. Ground Water, 49(6):932-945.

Spitler, J. D., and Gehlin, S. 2015. Thermal response testing for ground source heat pump systems—An historical review. Renewable and Sustainable Energy Reviews, 50:1125-1137.

Wang, H., Qi, C., Du, H., and Gu, J. 2009. Thermal performance of borehole heat exchanger under groundwater flow: A case study from Baoding. Energy and Buildings, 41(12):1368-1373.

Wang, H., Qi, C., Du, H., and Gu, J. 2010. Improved method and case study of thermal response test for borehole heat exchangers of ground source heat pump system. Renewable Energy, 35(3):727-733.

Witte, H. J. L. 2013. Error analysis of thermal response tests. Applied Energy, 109:302-311. 